\title{
Unit of Flow Rate
}

National Cancer Institute

\section{Source}

National Cancer Institute. Unit of Flow Rate. NCI Thesaurus. Code C48567.

A unit of measurement of substance that passes through or onto a given area per unit of time. 